\title{
The Frequency and Significance of Radiologically Detected Indeterminate Pulmonary Nodules in Patients with Colorectal Cancer
}

\author{
Yelda Varol ${ }^{a} \quad$ Umut Varol $^{b} \quad$ Burcak Karaca $^{b} \quad$ Bulent Karabulut $^{b}$ Canfeza Sezgin $^{b}$ \\ Ruchan Uslu ${ }^{b}$ \\ ${ }^{a}$ Department of Chest Diseases, Izmir M. Enver Senerdem Torbalı Government Hospital, and ${ }^{b}$ Department of \\ Medical Oncology, Faculty of Internal Medicine, Ege University, Izmir, Turkey
}

\section{Key Words}

Colorectal cancer • Prognosis • Pulmonary nodules

\begin{abstract}
Objective: To investigate the frequency and significance of pulmonary nodules in patients with colorectal cancer (CRC). Subjects and Methods: Medical records of 1,344 patients with CRC who underwent thoracic computerized tomography scans between January 2003 and December 2009 were reviewed. Those with any distant metastatic disease or who were already known to have pulmonary malignancies were excluded. Number, size, shape and location of the nodules were evaluated. A multivariate analysis was performed to determine the predictive factors for evidence of metastases. Results: Of the 1,344 patients, 55 (4.09\%) had nodules that met the criteria of an indeterminate pulmonary nodule. The mean follow-up time was $25 \pm 17.9$ months and the mean time to develop pulmonary metastasis was $15.5 \pm$ 6.4 months. The nodules of 17 (30.9\%) patients showed progression at follow-up; 8 had metastasized. Multivariate analysis showed multiple indeterminate pulmonary nodules $(p=$ $0.006)$ of parenchymal localization $(p=0.016)$ with an irregular border ( $p=0.002)$, which is predictive of metastatic disease. Conclusion: Our study has shown that multiple indeterminate pulmonary nodules with an irregular border in a
\end{abstract}

parenchymal location were more likely to represent metastatic disease. However, the frequency of the occurrence of indeterminate pulmonary metastases of CRC was low.

Copyright $\odot 2012$ S. Karger AG, Basel

\section{Introduction}

Colorectal cancer (CRC) is one of the most commonly diagnosed cancers and a common cause of cancer-related mortality in the world [1]. The mortality of CRC has declined over the last 25 years, with a well-documented 20 $25 \%$ reduction in CRC mortality rate from 1990 to 2003, due to well-established screening and surgical techniques as well as the development of new targeted therapies for treatment [1-3]. In general, 5-fluorouracil-based treatment schedules of either neoadjuvant chemotherapy and/ or radiotherapy before surgery or adjuvant chemotherapy treatment are offered to minimize the risk of recurrence and improve the overall outcome.

In recent years, radiological techniques have often been used for both screening or follow-up procedures of different types of cancer. Among these, computed tomographic (CT) scanning has become an important complementary tool for the clinician. It is commonly used to diagnose malignancies, evaluate treatment responses, and

\section{KARGER}

Fax +4161306 1234

E-Mail karger@karger.ch

www.karger.com
(C) 2012 S. Karger AG, Basel

1011-7571/12/0215-0457\$38.00/0

Accessible online at:

www.karger.com/mpp
Dr. Umut Varol, MD

Ege University School of Medicine

Tulay Aktas Oncology Hospital

Bornova, Izmir (Turkey)

Tel. +90 232390 2388, E-Mail varolumut@yahoo.com 
monitor disease recurrence. Following routine staging procedures using CT scans, an increasing number of patients have been shown to have indeterminate pulmonary nodules with no evidence of metastatic disease elsewhere $[4,5]$. These indeterminate pulmonary nodules in patients with CRC create a clinical dilemma. Such nodules may either represent scars, metastatic disease, or newly diagnosed primary cancer. In daily clinical practice, it is not certain whether such patients should be considered to have early CRC and managed accordingly using treatments with a curative intent or considered to have metastatic disease $[4,6,7]$. Hence, the aim of this study was to determine the incidence, characteristics and outcomes of CRC patients with suspicious pulmonary nodules.

\section{Subjects and Methods}

The medical records of 1,344 patients with CRC referred to the Medical Oncology Department of the Faculty of Medicine of Ege University between January 2003 and December 2009 were reviewed. Approval for the study was obtained from the Institutional Review Board. Patients were staged according to their pathological and imaging findings (7th edition of the AJCC Cancer Staging Manual). Patients with at least one pulmonary nodule identified on thoracic CT scan at initial staging before treatment were included in the study. All CTs were performed by a multidetector CT (Toshiba Aquilion 16S). Multiple radiologists in the department read and reported the 1,344 scans. The scans which had suspicious pulmonary nodules were read by a consultant pulmonary radiologist. Patients with any distant metastasis, including liver or mediastinum, and patients already known to have pulmonary malignancies, including primary lung cancer, were excluded. Also excluded were patients who did not participate in the 1 -year follow-up. The radiological follow-up for pulmonary nodules was discontinued if the patient developed any other metastasis during the follow-up period.

A suspicious, indeterminate pulmonary nodule was defined as one or more radiological lesions within the pulmonary parenchyma which were $<1.5 \mathrm{~cm}$ in size. Lesions which were amenable to fine needle aspiration or biopsy were not considered because of their size.

Follow-up data were obtained from the medical records: age, sex, date of diagnosis, date of initial staging, smoking history, cancer localization, staging, histological information, all subsequent treatments (chemotherapy, radiation therapy, surgery), and size and number of pulmonary nodules. The characteristics of pulmonary nodules (i.e. calcification, border regularity, proximity to pleura), time to disease progression and existence of mediastinal lymph nodes $>1 \mathrm{~cm}$ were analyzed.

Assessments of nodules were performed with CT scans every 8-12 weeks until disease progression. During follow-up, the nodules that showed progression were divided into two groups: the first group was categorized 'increase in number or size of nodules without evidence of metastatic disease' (a newly found $0.4-\mathrm{cm}$ nodule on CT scan or a $0.6-\mathrm{cm}$ nodule showing progression to
Table 1. Characteristics of the study population

\begin{tabular}{ll}
\hline Number of patients & 55 \\
Male sex & $40(72.7 \%)$ \\
Age, years & $64.93(37-84)$ \\
Ever smoker & $20(36.4 \%)$ \\
Nodule number & $2.78(1-15)$ \\
\hline
\end{tabular}

Table 2. Histopathological findings from the primary tumors of 55 patients

$\begin{array}{lr}\text { Histological grade, } \mathrm{n}(\%) & \\ \text { Good differentiation } & 6(10.9) \\ \text { Moderate differentiation } & 41(74.5) \\ \text { Poor differentiation } & 8(14.5) \\ \text { Number of lymph nodes, median (range) } & \\ \quad \text { Positive lymph nodes } & 2.33(0-16) \\ \text { Lymph nodes extracted } & 15.24(2-39)\end{array}$

$0.9 \mathrm{~cm}$ on different CT sections were not accepted as metastasis); the second group was 'progression of pulmonary nodules accepted as metastasis', indicated by an increase in the number and/or size of the nodules of more than $1.5 \mathrm{~cm}$ or with a high standard uptake value (SUV) of the nodule on PET/CT image.

Statistical Analysis

SPSS 11.0 was used for statistical analysis. Nonparametric test of Mann-Whitney $U$ tests and $\chi^{2}$ tests were performed for statistic evaluation. Logistic regression method was used for multivariate analysis; $\mathrm{p}<0.05$ was considered significant. Descriptions of all available variables are given as numbers and percentages; results are expressed as means \pm standard deviations.

\section{Results}

\section{Patient Characteristics}

Demographic data are shown in table 1. Of the 1,344 patients, $55(4.09 \%)$ patients had indeterminate pulmonary nodules. Of the 55, $40(72.7 \%)$ were men and 35 (63.6\%) nonsmokers. Fifty-four patients underwent surgery and pathological TNM was used for staging. The remaining patient was treated with chemotherapy and staged clinically. The histological data of the primary tumor of the patients are summarized in table 2 .

Stratification of the stage of primary disease was as follows: stage 1: 2 (3.6\%); stage 2: 22 (40\%); stage 3: 24 $(43.6 \%)$, and stage $4: 1(1.8 \%)$, at the time of the diagnosis (table 3). 
Table 3. TNM staging of the patients based on the 7th edition of the AJCC Cancer Staging Manual

\begin{tabular}{lc}
\hline Stage & $n(\%)$ \\
\hline 1 & $2(3.6)$ \\
$2 \mathrm{a}$ & $21(38.2)$ \\
$2 \mathrm{c}$ & $1(1.8)$ \\
$3 \mathrm{a}$ & $1(1.8)$ \\
$3 \mathrm{~b}$ & $23(41.8)$ \\
$3 \mathrm{c}$ & $6(10.9)$ \\
$4 \mathrm{a}$ & $1(1.8)$ \\
\hline
\end{tabular}

Table 4. The characteristics of solitary and multiple nodules

\begin{tabular}{lcc}
\hline Nodule size & Solitary, $\mathrm{n}(\%)$ & Multiple, $\mathrm{n}(\%)$ \\
\hline$<0.5 \mathrm{~cm}$ & $16(66.7)$ & $15(48.4)$ \\
max. $0.5-1 \mathrm{~cm}$ & $6(25.0)$ & $12(38.7)$ \\
max. $1-1.5 \mathrm{~cm}$ & $2(8.3)$ & $4(12.9)$ \\
\hline Total & $24(100.0)$ & $31(100.0)$ \\
\hline
\end{tabular}

The patient with stage 4 disease was included in this study. The multidisciplinary council accepted the patient's 5 pulmonary nodules as metastases, which were below $1.5 \mathrm{~cm}$.

This patient did not undergo surgery for his primary cancer and was followed up for 16 months. After this period, his pulmonary nodules increased in size and number and were confirmed as metastasized.

Tumor localization occurred in the rectum for 22 (40\%) patients and in the colon for the remaining 33 $(60 \%)$ patients. The majority of the patients $(44,80 \%)$ had adjuvant chemotherapy, while $18(32.7 \%)$ had adjuvant radiotherapy.

\section{Morphology and Position of Nodules}

The size of the nodules was as follows: nodules $\geq 1 \mathrm{~cm}$ $(1-1.5 \mathrm{~cm}): 6(10.9 \%)$ patients; $0.5-1 \mathrm{~cm}: 18$ (32.7\%) patients; $\leq 0.5 \mathrm{~cm}: 31$ (56.4\%) patients. Pulmonary nodules were described as solitary in 24 patients and multiple in 31. The characteristics of solitary and multiple nodules are summarized in table 4.

In 36 (65.5\%) patients, the lesions were located peripherally and described as being subpleural parenchymal. Of the remaining 19 (34.5\%) patients, the lesions were scattered throughout the lungs and were described as paren- chymal. Nine (16.4\%) patients showed calcification associated with the nodules. The characteristics of the nodules appeared to fall into two categories, rounded and angular. The angular nodules were not completely round with straight, angular edges. The nodules were regular in shape for 46 (83.65) patients while 9 (16.4) patients had irregular pulmonary nodules.

\section{Outcome Data}

At follow-up, 17 (30.9\%) patients had progression. Of the 17 patients, 8 (47\%) with progressed nodules were acknowledged to have metastasized. All 8 patients received chemotherapy. The patients with multiple nodules were significantly $(\mathrm{p}=0.006)$ more likely to have progressive nodules with metastatic characteristics during follow-up. Indeterminate pulmonary nodules were considered unlikely to be related to CRC if there was no significant radiologic change in the size of the lesion or if they resolved after 12 months from the initial CT thorax scan.

There was a statistically significant association between primary tumor localization and pulmonary metastasis. The nodules of the patients with carcinoma of the rectum showed greater pulmonary metastasis than patients with carcinoma of the colon $(\mathrm{p}=0.037)$. The majority of the patients with carcinoma of the rectum were stage $3 \mathrm{~b}(16,72.7 \%)$, while the majority of the patients with carcinoma of the colon were stage $2 \mathrm{a}(20,60.6 \%)$ (table 3).

The mean follow-up time was 25 months (range: 5-78, interquartile range: $18-45)$ and the mean time to metastasis was 15.5 months (range: $1-37$, interquartile range: 4.25-19). Due to the spontaneous regression of nodules within 12 months after diagnosis, 3 cases were excluded from follow-up for pulmonary nodules $(5,9,11$ months).

Nine patients with nodules showed calcification, but none showed progression, which was statistically significant $(\mathrm{p}=0.026)$ compared to noncalcific nodules. Those with parenchymal nodules (6 of 19) were significantly more likely to have progressive disease than those with subpleural parenchymal nodules ( 2 of 36$)(p=0.016)$.

There was a statistically significant association between the irregularity of a nodule's border and recognition of progression to metastasis $(\mathrm{p}=0.002)$ (table 5). A nodule with an irregular border increased the risk of metastasis 28.35 times. There was no statistically significant association between the disease stage and the presence of indeterminate pulmonary nodules or their metastatic progression ( $p>0.05)$. Age, gender, a history of smoking, active cancer therapy, and number of positive lymph nodes $(p>0.05)$ all did not have significant correlation to 
Table 5. Nodule outcome of patients with or without border regularity

\begin{tabular}{|c|c|c|c|c|c|c|}
\hline & \multicolumn{3}{|c|}{ Pulmonary metastasis } & \multicolumn{3}{|c|}{ Increasing number and size of nodules } \\
\hline & stable & metastasis & $\mathrm{p}$ & not increased & increased & $\mathrm{p}$ \\
\hline Regular border & $43(93.5 \%)$ & $3(6.5 \%)$ & \multirow{2}{*}{0.002} & $36(78.3 \%)$ & $10(21.7 \%)$ & \multirow{2}{*}{0.002} \\
\hline Irregular border & $4(44.4 \%)$ & $5(55.6 \%)$ & & $2(22.2 \%)$ & $7(77.8 \%)$ & \\
\hline Total & $47(85.5 \%)$ & $8(14.5 \%)$ & & $38(69.1 \%)$ & $17(30.9 \%)$ & \\
\hline
\end{tabular}

progression of the pulmonary nodules. There was no statistical significance between the size of the nodules and their progression to metastasis $(\mathrm{p}>0.05)$.

\section{Discussion}

In our study, there were 55 (4.09) patients with indeterminate pulmonary nodules and those with multiple nodules showed significantly more probability of being metastatic compared to the solitary ones. However, in the literature, a similar study of breast cancer patients with indeterminate pulmonary nodules noted that there was no change in $89 \%$ of multiple subcentimeter nodules, whereas all nodules $>1 \mathrm{~cm}$ had progressed [8]. Therefore, it must be concluded that there are not enough definitive data explaining the relationship between metastasis and the multiplicity of suspicious pulmonary nodules.

This finding is similar to a study [9] involving patients who had subcentimeter pulmonary nodules and who had undergone hepatic resection due to metastatic CRC. Thirty-five percent of patients' nodules were proven to be metastatic during the follow-up period. Half of these metastatic nodules were demonstrated by the radiological increase in size or number while the other half was established histologically. According to our findings, $14 \%$ of our patients $(n=8)$ developed metastases during their follow-up.

The nodules of patients with carcinoma of the rectum showed more pulmonary metastases than those of the patients with carcinoma of the colon. A probable explanation is that the majority of the patients with carcinoma of the rectum were stage $3 \mathrm{~b}$, while the majority of the patients with carcinoma of the colon were stage $2 \mathrm{a}$. Also, more patients with carcinoma of the rectum manifested nodules larger than $1 \mathrm{~cm}$. Both stage and size of nodules could account for the difference between these two similar malignancies as well as the different pattern of vascularization in the rectum and the colon.
According to the solitary pulmonary screening program of Erasmus et al. [10] for noncalcified nodules $<0.5 \mathrm{~cm}$ in diameter detected in CTs, there is no need to justify immediate diagnostic workup; however, these nodules should be screened annually. If the nodule does not exhibit unequivocally benign characteristics (benign pattern of calcification, smooth margin, size less than $20 \mathrm{~mm}$ ), then follow-up with thin section CT is advised every 3 months and subsequently at 6, 12 and 24 months [10]. In our study, none of the patients with indeterminate pulmonary nodules with calcification showed progression, which was consistent with existing data. Their follow-up was done with CT scan every 3 months and the 9 patients with calcified pulmonary nodules were then accepted as nonmetastatic.

Our finding that peripherally located nodules were less likely to be progressive than parenchymal ones is similar to the finding of Takashima et al. [11] in which subpleural localization was more frequently benign than malignant lesions.

There was a statistically significant association between a nodule's irregular border, both with regard to the increase in the number and size of nodules, and with the progression of nodules acknowledged to be metastatic. A smooth margin most likely indicates a benign lesion. This finding was confirmed by a previous study by Feng Li et al. [12], who showed that nodules with a smooth margin were benign on thin-section $\mathrm{CT}$, while $\mathrm{Xu}$ et al. [13] showed that solid pulmonary nodules with smooth margins compared to lobulated or spiculated ones indicate a benign character.

While age, gender, a history of smoking, active cancer therapy, number of positive lymph nodes of the primary tumor all did not have any significant impact on the progression of the pulmonary nodules in our study, other studies showed an association between cigarette smoking and progression of pulmonary nodules in various malignancies $[14,15]$. 
PET scanning is recognized to be of diagnostic benefit in assessing the likelihood of malignancy in solid pulmonary nodules $>1 \mathrm{~cm}$ in diameter, and an SUV $>3$ is generally accepted as sensitive and specific enough for cancer [16]. However, this diagnostic modality cannot determine if the lesion is primary or secondary. Eighteen out of 55 patients had undergone PET scanning and 8 patients who were accepted as metastatic also showed an SUV $>3$ confirming the diagnosis. However, if a nodule is $<1 \mathrm{~cm}$ in diameter or subsolid, sensitivity and specificity decline in PET [17]. Therefore, in indeterminate pulmonary nodules below $1 \mathrm{~cm}$, this dilemma still needs further investigation.

One of the limitations of our study was the absence of histologic confirmation of progressive pulmonary lesions, which would have provided more accurate evidence than those based apparently on CT investigations alone. Biopsy was not done because of well-known ethical issues with biopsy in such cases, due to exacerbation of small lesions in the lung with a particularly high risk of complications [18-21]. Much more importantly, since the study was retrospective, CT scans were not administered in a standardized fashion.

\section{Conclusion}

Our study showed that indeterminate multiple pulmonary nodules with an irregular border in a parenchymal location were more likely to represent metastatic disease. As more data become available from the increasing sensitivity and specificity of radiologic imaging techniques, a more definitive description of the characteristics of the nodules may lead to a better understanding of the frequency and significance of pulmonary nodules in patients with CRC.

\section{References}

$>1$ Parkin DM, Bray F, Ferlay J, Pisani P: Global cancer statistics, 2002. CA Cancer J Clin 2005;55:74-108.

-2 Sanli UA, Karabulut B, Uslu R, Korkut M, Goker M: Single-agent irinotecan for recurrent/metastatic colorectal cancer: a retrospective analysis. Med Princ Pract 2006;15: 288-292.

-3 Teke Z, Nessar G, Kiremitci S, Aksoy E, Elbir $\mathrm{OH}$ : Hepar lobatum carcinomatosum associated with metastatic rectal carcinoma: an unusual cause of liver dysmorphy. Med Princ Pract 2011;20:93-96.

4 Khokhar S, Vickers A, Moore MS, Mironov S, Stover DE, Feinstein MB: Significance of non-calcified pulmonary nodules in patients with extrapulmonary cancers. Thorax 2006; 61:331-336.

$>5$ MacMahon H, Austin JH, Gamsu G, Herold CJ, Jett JR, Naidich DP, Patz EF Jr, Swensen SJ: Guidelines for management of small pulmonary nodules detected on CT scans: a statement from the Fleischner Society. Radiology 2005;237:395-400.

$\checkmark 6$ Mery CM, Pappas AN, Bueno R, Mentzer SJ, Lukanich JM, Sugarbaker DJ, Jaklitsch MT: Relationship between a history of antecedent cancer and the probability of malignancy for a solitary pulmonary nodule. Chest 2004; 125:2175-2181.

7 Libby DM, Smith JP, Altorki NK, Pasmantier MW, Yankelevitz D, Henschke CI: Managing the small pulmonary nodule discovered by CT. Chest 2004;125:1522-1529.

$>8$ Lee B, Lim A, Lalvani A, Descamps MJ, Leonard R, Nallamala S, Lewis JS, Coombes
RC, Stebbing J: The clinical significance of radiologically detected silent pulmonary nodules in early breast cancer. Ann Oncol 2008;19:2001-2006.

-9 Maithel SK, Ginsberg MS, D’Amico F, DeMatteo RP, Allen PJ, Fong Y, Blumgart LH, Jarnagin WR, D'Angelica MI: Natural history of patients with subcentimeter pulmonary nodules undergoing hepatic resection for metastatic colorectal cancer. J Am Coll Surg 2010;210:31-38.

10 Erasmus JJ, Connolly JE, McAdams HP, Roggli VL: Solitary pulmonary nodules: 1. Morphologic evaluation for differentiation of benign and malignant lesions. Radiographics 2000;20:43-58.

11 Takashima S, Sone S, Li F, Maruyama Y, Hasegawa M, Matsushita T, Takayama F, Kadoya M: Small solitary pulmonary nodules $(<$ or $=1 \mathrm{~cm})$ detected at population-based CT screening for lung cancer: reliable high-resolution CT features of benign lesions. AJR Am J Roentgenol 2003;180:955-964.

12 Li F, Sone S, Abe H, Macmahon H, Doi K: Malignant versus benign nodules at $\mathrm{CT}$ screening for lung cancer: comparison of thin-section CT findings. Radiology 2004; 233:793-798.

13 Xu DM, van Klaveren RJ, de Bock GH, Leusveld A, Zhao Y, Wang Y, Vliegenthart R, de Koning HJ, Scholten ET, Verschakelen J, et al: Limited value of shape, margin and CT density in the discrimination between benign and malignant screen detected solid pulmonary nodules of the NELSON trial. Eur J Radiol 2008;68:347-352.
14 Murin S, Inciardi J: Cigarette smoking and the risk of pulmonary metastasis from breast cancer. Chest 2001;119:1635-1640.

15 Abrams JA, Lee PC, Port JL, Altorki NK, Neugut AI: Cigarette smoking and risk of lung metastasis from esophageal cancer. Cancer Epidemiol Biomarkers Prev 2008; 17: 2707-2713.

16 Gould MK, Maclean CC, Kuschner WG, Rydzak CE, Owens DK: Accuracy of positron emission tomography for diagnosis of pulmonary nodules and mass lesions: a metaanalysis. JAMA 2001;285:914-924.

17 O JH, Yoo IeR, Kim SH, Sohn HS, Chung SK: Clinical significance of small pulmonary nodules with little or no 18 F-FDG uptake on PET/CT images of patients with nonthoracic malignancies. J Nucl Med 2007;48:15-21.

18 Kodish E, Stocking C, Ratain MJ, Kohrman A, Siegler M: Ethical issues in phase I oncology research: a comparison of investigators and institutional review board chairpersons. J Clin Oncol 1992;10:1810-1816.

19 Agulnik M, Oza AM, Pond GR, Siu LL: Impact and perceptions of mandatory tumor biopsies for correlative studies in clinical trials of novel anticancer agents. J Clin Oncol 2006;24:4801-4807.

20 Cannistra SA: Performance of biopsies in clinical research. J Clin Oncol 2007;25:14541455.

21 Helft PR, Daugherty CK: Are we taking without giving in return? The ethics of research-related biopsies and the benefits of clinical trial participation. J Clin Oncol 2006;24:4793-4795. 